\title{
Clinico-Pathological Evaluation of Hepatobiliary Disorders in Dogs
}

\author{
K. Lakshmi ${ }^{1}$ and K. Padmaja ${ }^{2}$ \\ ${ }^{1}$ Department of Veterinary Medicine, College of Veterinary Science, Korutla, \\ Jagityal district, Telangana state, India \\ ${ }^{2}$ Department of Veterinary Medicine, College of Veterinary Science, Rajendranagar, India \\ *Corresponding author
}

Keywords

Clinical signs,

Pathology,

Hepatobiliary

disorders, Dogs

Article Info

Accepted:

15 January 2021

Available Online:

10 February 2021

\section{A B S T R A C T}

A study was conducted on 140 dogs diagnosed for hepatobiliary disorders to evaluate symptomatology and pathological investigations. Common clinical signs observed in hepatobiliary disorders affected dogs were inappetance and anorexia, vomition, anemia, diarrhea, pyrexia, lethargy, icterus, abdominal pain, emaciation, ascites, weight gain, weight loss, respiratory distress, limb edema, nervous signs, polyuria and polydipsia. Significantly decreased $\mathrm{Hb}$ and TEC with elevated TLC and neutrophil count were common hematological abnormalities. Similarly, elevated activity of ALT, AST, ALP, GGT, total bilirubin, direct bilirubin and globulin with decreased levels of total protein, albumin and glucose were common biochemical findings recorded in all hepatobiliary disorders.

\section{Introduction}

Liver plays a central role in a diverse array of processes including carbohydrate, lipid and protein metabolism; storage of vitamins, trace minerals, fat, glycogen and immune regulation. Liver is uniquely susceptible to damage as a consequence of its role as a filter for portal blood, metabolism of endogenous metabolites and xenobiotics (Cynthia, 2013). Diagnosis of various conditions of liver and gall bladder based on ultrasonography should be complimented with clinico-haemato- biochemical parameters. Clinical signs of hepatobiliary disease in dogs can be extremely variable, ranging from anorexia and weight loss to abdominal effusion, jaundice and hepatic coma. Symptoms, clinical signs and diagnostic results reflect impairments in these functions (Meyer and Rothuizen, 2013).

Common clinical manifestations include anorexia, vomition, ascites, jaundice, constipation or diarrhoea, polyurea and polydipsia, weight loss and coagulation abnormalities. Serum ALT and AST activities 
are the two most commonly measured markers of hepatocellular leakage in dogs(Centre, 2015).

\section{Materials and Methods}

Dogs presented to Veterinary Hospital, Bhoiguda with the clinical signs of anorexia, ascites, jaundice, pale mucous membranes, vomition, lethargy, polyuria and polydipsia or other manifestations suggestive of hepatobiliary disorders were selected. These were examined clinically as per the standard methods of clinical examination (Kelly, 1984).

Blood was collected from the peripheral (cephalic/saphenous)veins of dogs suffering with hepatobiliary disorders in dogs using three sterile vaccutainers containing EDTA (ethylene di amine tetra acetic acid- $2 \mathrm{mg} / \mathrm{ml}$ blood)and sodium fluoride as anticoagulants for estimation of hematological parameters and blood glucose, respectively. Similarly, blood was also collected into sterile clean vaccutainers containing clot activator for serum separation. This sample was centrifuged at 3000rpmfor 15 minutes and the serum collected was transferred into Eppendorff tubes and stored at $-20^{\circ} \mathrm{C}$ for estimation of biochemical parameters.

\section{Results and Discussion}

One hundred and forty dogs that were diagnosed for various hepatobiliary disorders, history and clinical manifestations like inappetance and anorexia, vomition, anemia, diarrhoea, pyrexia, lethargy, icterus, abdominal pain, emaciation, ascites, weight gain, weight loss, respiratory distress, limb edema, nervous signs and polyuria and polydipsia were reported (Fig: 1-4). The present findings corroborate with Tantary et al., (2014) and Maddison (2016) who reported clinical signs of hepatobiliary disease in dogs as inappetance, vomition, weight loss, abdominal distension, polydipsia, cutaneous lesions and fever. Clinical signs of hepatobiliary disease in dogs can be extremely variable, ranging from anorexia and weight loss to abdominal effusion, jaundice and hepatic coma. Inappetance and anorexia was found in most of the cases in the present study as a non-specific sign of hepatobiliary disorders and similar observations were made by Mircean et al., (2008). Vomiting associated with liver dysfunctions could be attributed to the direct stimulation of the vomiting centre by chemoreceptor trigger zone (CTZ) in the fourth ventricle of the brain by the endotoxins that were not cleared by the diseased liver.

Anemia was attributed to chronic nature of this liver disease due to increased transient time of erythrocytes through the spleen due to reduced portal blood flow and or fragility of red cells due to high levels of bile acids. Non regenerative anemia was a common finding particularly in chronic hepatic disease as an expression of catabolism and slight deficiencies of iron and B complex vitamins. Icterus or Jaundice reported in the present study was caused by the accumulation of bilirubin in the tissues.

Ascites in the present study was a result of disruption of starling forces in local capillary beds with diffusion cross the serosa into the peritoneal cavity (Mansfield, 2013). Polyuria and polydipsia have been attributed to the impaired adrenal steroid metabolism, altered portal vein osmoreceptor, loss of renal medullary concentration gradient and encephalopathy.

Polyuria resulted from inadequate production of functional anti diuretic hormone (ADH), lack of appropriate renal response to anti diuretic hormone and osmotic diuresis. Polydipsia may also occur when the thirst centre in the anterior hypothalamus is stimulated (Polzin, 2013). 
Table.1 Mean hematological findings in healthy and hepatobiliary disorders affected dogs.

\begin{tabular}{|c|c|c|c|}
\hline S.No & Parameter & $\begin{array}{c}\text { Healthy } \\
\text { control }\end{array}$ & $\begin{array}{c}\text { Hepatobiliary } \\
\text { disorders affected } \\
\text { dogs }\end{array}$ \\
\hline $\mathbf{1}$ & Hb ( g/dl) & $12.92 \pm 0.44$ & $9.06 \pm 0.24^{* *}$ \\
\hline $\mathbf{2}$ & TEC $(\mathbf{X ~ 1 0} / \boldsymbol{\mu L})$ & $7.19 \pm 0.23$ & $4.64 \pm 0.13^{* * *}$ \\
\hline $\mathbf{3}$ & TLC(X 10 $\mathbf{3} / \boldsymbol{\mu})$ & $8.66 \pm 1.65$ & $23.73 \pm 0.92^{* *}$ \\
\hline $\mathbf{4}$ & PCV(\%) & $41.73 \pm 1.34$ & $38.81 \pm 3.69$ \\
\hline $\mathbf{5}$ & Neutrophils (\%) & $58.98 \pm 2.70$ & $80.04 \pm 1.51^{*}$ \\
\hline $\mathbf{6}$ & Lymphocytes (\%) & $31.90 \pm 0.75$ & $26.61 \pm 4.07$ \\
\hline $\mathbf{7}$ & Monocytes (\%) & $2.18 \pm 0.29$ & $2.45 \pm 0.88$ \\
\hline $\mathbf{8}$ & Eosinophils (\%) & $2.50 \pm 0.18$ & $1.97 \pm 0.10$ \\
\hline $\mathbf{9}$ & Basophils (\%) & $0.48 \pm 0.24$ & $0.52 \pm 0.12$ \\
\hline
\end{tabular}

Significant at $(\mathrm{P}<0.05),{ }^{* * *}$ Significant at $(\mathrm{P}<0.01)$

Table.2 Mean biochemical findings in healthy and hepatobiliary disorders affected $\operatorname{dog} s$

\begin{tabular}{|c|c|c|c|}
\hline S.No & Parameter & $\begin{array}{c}\text { Healthy } \\
\text { control }\end{array}$ & $\begin{array}{c}\text { Hepatobiliary } \\
\text { disorders affected } \\
\text { dogs }\end{array}$ \\
\hline $\mathbf{1 .}$ & ALT(U/L) & $32.80 \pm 1.60$ & $203.19 \pm 19.16^{* *}$ \\
\hline $\mathbf{2 .}$ & AST(U/L) & $43.05 \pm 1.22$ & $184.84 \pm 22.32^{* *}$ \\
\hline $\mathbf{3 .}$ & ALP(U/L) & $59.62 \pm 2.08$ & $284.82 \pm 18.39^{* *}$ \\
\hline $\mathbf{4 .}$ & GGT(U/L) & $3.04 \pm 0.15$ & $6.64 \pm 0.51^{*}$ \\
\hline $\mathbf{5 .}$ & TB(m g/dl) & $0.45 \pm 0.03$ & $1.17 \pm 0.04$ \\
\hline $\mathbf{6 .}$ & DB( mg/dl) & $0.19 \pm 0.02$ & $0.75 \pm 0.05$ \\
\hline $\mathbf{7 .}$ & Total Protein $\mathbf{( g / d l )}$ & $6.22 \pm 0.03$ & $4.77 \pm 0.10^{* *}$ \\
\hline $\mathbf{8 .}$ & Albumin( g/dl) & $2.81 \pm 0.07$ & $2.01 \pm 0.03^{* *}$ \\
\hline $\mathbf{9 .}$ & Globulins( g/dl) & $3.41 \pm 0.07$ & $3.43 \pm 0.01^{* *}$ \\
\hline $\mathbf{1 0 .}$ & Glucose (mg/dl) & $108.24 \pm 1.87$ & $90.86 \pm 1.39^{* *}$ \\
\hline
\end{tabular}

Significant at $(\mathrm{P}<0.05), \quad{ }^{* *}$ Significant at $(\mathrm{P}<0.01)$ 
Fig.1 Yellowish discoloration of conjunctival, buccal mucous membranes
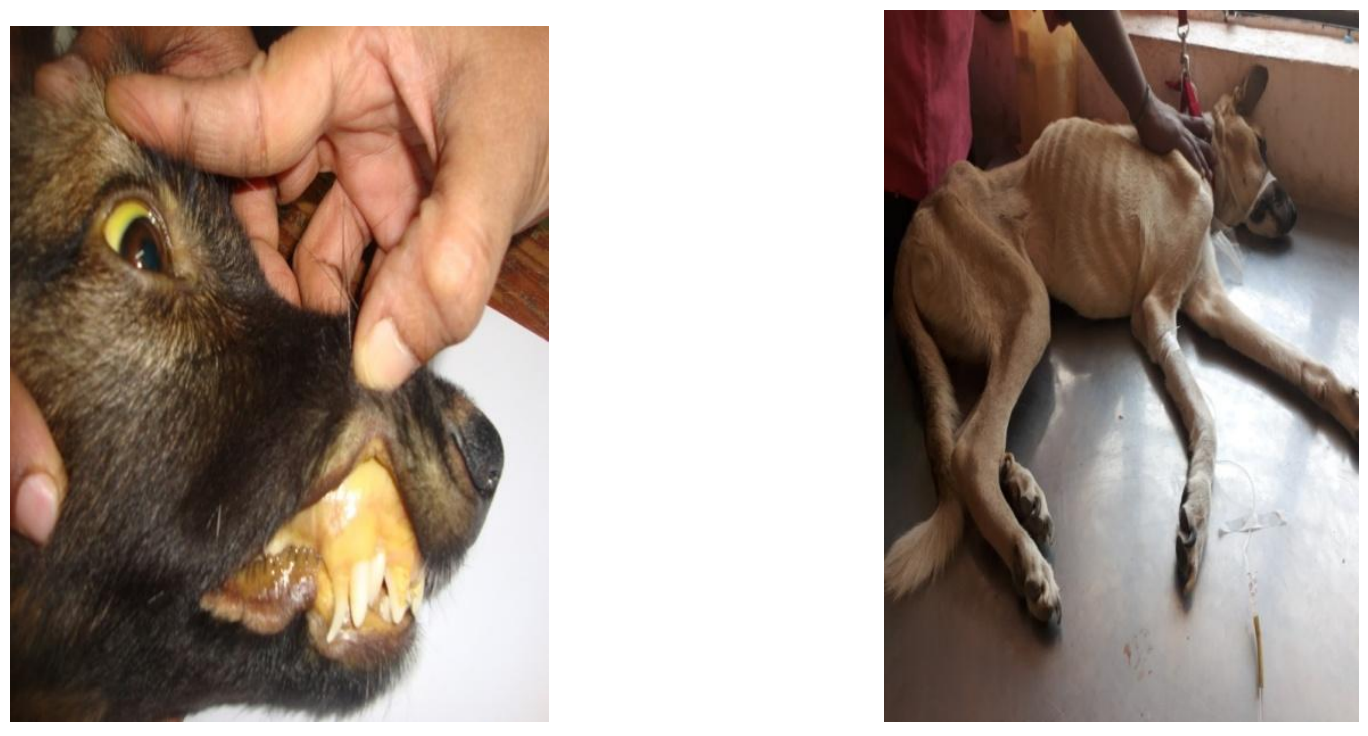

Fig.3 Anemia- Pale buccal mucous membranes

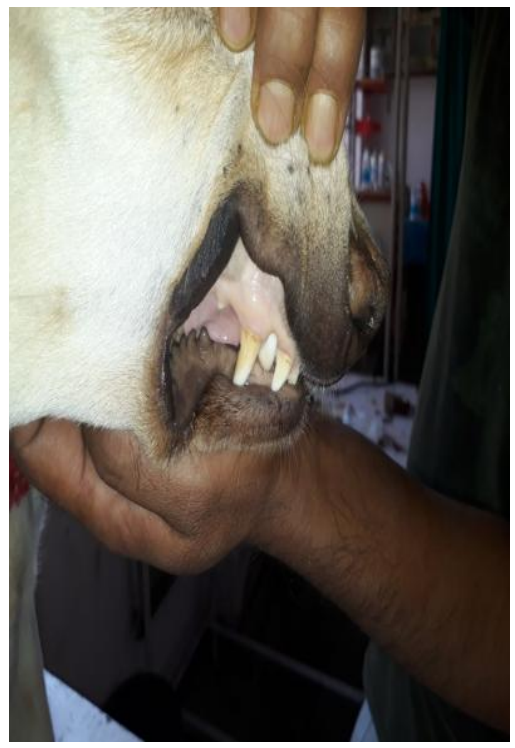

Fig.2 Emaciation

Fig.4 Ascites

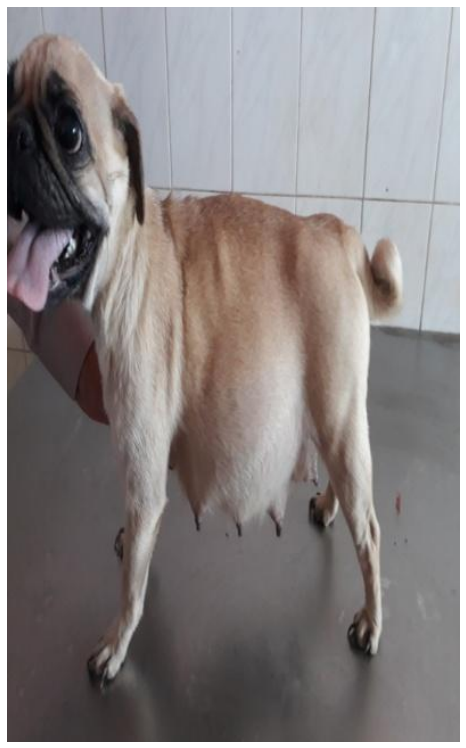


The mean hemoglobin (g/dl) levels in healthy control and hepatobiliary disorders affected dogs were $12.92 \pm 0.44$ and $9.06 \pm 0.24$. The mean total erythrocyte count $\left(\mathrm{x} 10^{6} / \mu \mathrm{l}\right)$ was $7.19 \pm 0.23$ and $4.64 \pm 0.13$. The mean total leucocyte count $\left(\mathrm{x} 10^{3} / \mu \mathrm{l}\right)$ was $8.66 \pm 1.65$ and $23.73 \pm 0.92$. The mean PCV (\%)was $41.73 \pm 1.34$ and 38.81 \pm 3.69 . The mean neutrophil count (\%) was $58.98 \pm 2.70$ and $80.04 \pm 1.51$. While, no significant change was observed with respect to lymphocytes, monocytes, eosinophils and basophils (Table1). Similar findings were reported earlier by Saravanan et al., (2014) and Bhadesiya et al., (2015). The reduction in the mean values of TEC might be due to the increased degradation of RBC. An increase in the mean values of total leucocyte count in the present study was characteristic of acute inflammatory conditions. Neutrophilic leucocytosis was a characteristic feature of ongoing acute inflammatory conditions which might be due to stress reactions in hepatopathy (Elhiblu et al., (2015).

The mean serum ALT activity of healthy and hepatobiliary disorders affected dogs on was $32.80 \pm 1.60$ and 203.19 \pm 19.16. The mean serum AST activity was $43.05 \pm 1.22$ and $184.84 \pm 22.32$. The mean serum ALP activity was $59.62 \pm 2.08$ and $284.82 \pm 18.39$. The mean serum GGT activity was 3.04 0.15 and $6.64 \pm 0.51$. The mean serum total protein concentration was $6.22 \pm 0.03$ and $4.77 \pm 0.10$. The mean serum albumin was $2.81 \pm 0.07$ and $2.01 \pm 0.03$. The mean serum globulin concentration was $3.41 \pm 0.07$ and $3.43 \pm 0.01$. The mean serum glucose concentration was

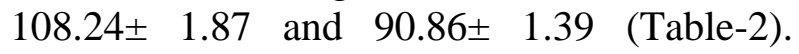
Serum ALT enzyme was a leakage marker, which is released as a result of hepatocyte damage. ALT and AST are indicative of altered hepatocellular membrane permeability, hepatocellular necrosis and inflammation with degree proportional to number of injured hepatocytes. Measuring AST levels is somewhat more sensitive but less specific for detecting hepatobiliary diseases (Webster, 2010).ALP is a membrane bound enzyme found on hepatocyte canalicular membrane and luminal surface of biliary epithelial cells and elevation in its level in dogs usually indicative of hepatic origin (Tantary et al., 2014).Moderate to marked increase in GGT levels were seen with intrahepatic and extrahepatic cholestasis, while mild elevation in GGT were seen with acute hepatocellular injury in dogs.

Hyperbilirubinemia could be attributed to the damage of the hepatocytes or obstruction of biliary tract associated with inflammation of hepatic parenchyma. Hypoprotenemia could be due to the disruption in the hepatic protein metabolism marked decline in diet intake, malabsorbtion and ongoing protein losing enteropathies like gastroenteritis, gastrointestinal ulcerations and chronic gastritis.

Hypoglycemia might be due to inappetance and anorexia complemented by malabsorbtion from intestines and results from decreased glycogenolysis and gluconeogenesis combined with hyperinsulinemia due to decreased hepatic metabolism (Bhadesiya et al., 2015).

Common clinical signs observed in hepatobiliary disorders affected dogs were inappetance and anorexia, vomition, anemia, diarrhea, pyrexia, lethargy, icterus, abdominal pain, emaciation, ascites, weight gain, weight loss, respiratory distress, limb edema, nervous signs, polyuria and polydipsia. Significantly decreased $\mathrm{Hb}$ and TEC with elevated TLC and neutrophil count were common hematological abnormalities. Similarly, elevated activity of ALT, AST, ALP, GGT, total bilirubin, direct bilirubin and globulin with decreased levels of total protein, albumin and glucose were common biochemical findings recorded in dogs affected with hepatobiliary disorders. 


\section{References}

Bhadesiya C M, Jani R G, Parikh P V, Pandey A M, Neha Rao and Shai A (2015). Haematobiochemistry and imaging study on ascites with hepatic and cardiac involvement in a German shepherd pup. International Research Journal of Chemistry. (11): 14-22.

Centre S A 2015. Overview of hepatic disease in small animals. Merck's Veterinary manual: 123-178.

Cynthia R W 2013.Weight loss and cachexia. In Washabau R J and Day M J. Textbook of canine and feline gastroenterology, Chapter 24. Elsevier publishers. pp: 174-176.

Elhiblu M A, Dua K, Mohindroo J, Mahajan S K, Sood N K, Dhaliwal P S 2015. Clinicohaemato-biochemical profile of dogs with liver cirrhosis. Veterinary World 8(4): 487-491.

Kelly W R 1984. Veterinary Clinical Diagnosis, III edn. Bailliere Tindall, London. pp: 26204.

Kumar M, Mondal D B, Saravanan M and Sharma K 2013.Therapeutic management of hepatobiliary dysfunction in canines, Intas polivet.14 (1): 117-120.

Maddison J E 2016. Diagnosis of hepatobiliary disease in dogs and cats- What do the tests really mean? Proceedings of $15^{\text {th }}$ World Small Animal Veterinary Association (WSAVA), $8^{\text {th }}$ federation of Small animal Practitioners Associations of India (FSAPA) Continuing education programme on companion animal practice. November $11^{\text {th }}-13^{\text {th }} 2016$ Chandigarh, India:1-44.
Mansfield C 2013. Ascites.In:Washabau R J and Day M J.Textbookof canine and feline gasteroenterology, Chapter 8., Elsevier publishers :80-86.

Meyer H P and Rothuizen J 2013. Liver. Chapter. 61 Liver In: Washabau R J and Day M J. Textbookof canine and feline gastero enterology. Elsevier publishers. PP: 849-972.

Mircean M G, Scurtu G I, Popovici C, Kiss T 2008. Observations regarding the comparative value of ultrasonography and laboratory diagnosis of hepatobiliary Diseases in Dogs. Bulletin UASVM, Veterinary Medicine 65(2):20-25.

Polzin D J (2013). Polyuria and Polydipsia. Chapter20. In: Washabau R J and Day M $\mathrm{J}$. Textbook of canine and feline gasteroenterology. Elsevier publishers. PP: 151-156.

Saravanan M, Mondal D B, Sharma K, Kumar M, Vijayakumar $\mathrm{H}$ and Sasikala V. 2014. Comprehensive study of hematobiochemical ascitic fluid analysis and ultrasonography in the diagnosis of ascites due to hepatobiliary disorders in dogs. Indian Journal of Animal Sciences.84 (5):503-506.

Tantary H A, Soodan J S, Chirag S, Ansari M M, Kumar S and Imtiyaz T 2014. Diagnostic studies in dogs with hepatic disorders. International Journal of Veterinary Science 3(4):210-215

Webster C R L 2010. History, clinical signs and physical findings in hepatobiliary disease. In Textbook of Veterinary internal Medicine, Ettinger $\mathrm{S} \mathrm{J}$ and Feldman E (eds) $7^{\text {th }}$ edition, St.Louis, Elsevier Saunders, pp: 1612-1618.

\section{How to cite this article:}

Lakshmi, K. and Padmaja, K. 2021. Clinico-Pathological Evaluation of Hepatobiliary Disorders in Dogs. Int.J.Curr.Microbiol.App.Sci. 10(02): 1733-1738. doi: https://doi.org/10.20546/ijcmas.2021.1002.204 